\title{
Palmerín de Olivia como enmienda del modelo amadisiano: El rechazo de la perfección arquetípica
}

\section{Palmerín de Olivia as an Amendment of the Amadisian Model: the Rejection of the Archetypical Perfection}

\author{
José Julio Martín Romero \\ Universidad de Jaén
}

\section{RESUMEN}

Ya en Palmerín de Olivia, la primera de las imitaciones de Amadís de Gaula, se detectan diferencias frente al paradigma amadisiano. Así, Palmerín, un héroe cuyo comportamiento es casi siempre ejemplar, en varias ocasiones revela debilidades que lo humanizan y que lo alejan de la perfección arquetípica de Amadís. El presente artículo rastrea y señala esos comportamientos poco caballerescos de Palmerín y los analiza como rasgos que singularizan este libro de caballerías frente a su modelo. Como resultado de todo esto, el presente estudio arroja luz sobre la configuración del género caballeresco y ayuda a comprender su heterogeneidad.

Palabras Clave: Amadís de Gaula, Palmerín de Olivia, libros de caballería, caballería.

\begin{abstract}
In Palmerin de Olivia, the first of the imitations of Amadís de Gaula, some differences from the amadisian paradigm can already be traced. Thus, Palmerín, a heroe whose behaviour is almost always exemplary, sometimes shows some weaknesses that make him more human and that distinguish this character from the archetypical perfection of Amadís. This article traces and points out these unknightly behaviours of Palmerín and analyses them as features that distinguish this book from its model. As a result, this study provides new data on the configuration and diversity of the chivalric romance as a genre.
\end{abstract}

Key words: Amadís de Gaula, Palmerín de Olivia, chivalric books, chivalry.

Seguramente en todo el ciclo artúrico no podrá encontrarse un caballero tan perfecto como Amadís y, mucho menos, como su hijo Esplandián, con la lógica excepción de Galaz, que es más santo que caballero ${ }^{1}$. Tampoco sería

\footnotetext{
${ }^{1}$ En Alvar (1991), trabajo verdaderamente imponente, se pueden revisar todos los personajes de la leyenda artúrica en distintos textos y comprobar hasta qué punto los caballeros
} 
fácil encontrar un héroe tan perfecto en las páginas de los libros de caballerías que surgieron al calor del éxito de los textos de Montalvo. Al contrario de lo que pudiera pensarse, no lo es Palmerín de Olivia, protagonista del primer libro de caballerías que tomó como modelo el Amadís de Gaula, pero con personajes ajenos a este ciclo. El análisis de algunos rasgos de Palmerín lleva a pensar que no se pretendía componer una imitación servil de la obra del regidor de Medina del Campo, sino más bien ofrecer una revisión de su materia y, aunque de una manera menos evidente que en el caso de Florisando, presentar una especie de enmienda a algunos rasgos de ese modelo, que en ocasiones parece incluso parodiar. Y es que Palmerín, a pesar de sus muchas virtudes y valores, no deja de mostrar algunos rasgos que lo humanizan en tanto que lo alejan del ideal de perfección representado por Amadís y Esplandián ${ }^{2}$.

El autor (¿autora? $\left.{ }^{3}\right)$ de Palmerín de Olivia demuestra un extraordinario interés por los aspectos psicológicos de sus personajes. Sus pasiones, sus debilidades, sus motivaciones ocultas son detalladas en el texto, de manera que el lector conoce sus intimidades y entiende mejor sus comportamientos y reacciones. Así, en esta obra se crea todo un entramado de intereses que determinan las amistades y los enfrentamientos. De manera explícita se van relatando las motivaciones - en muchas ocasiones no confesadas - de las acciones de los personajes. No es mi propósito aquí ofrecer un estudio pormenorizado de los aspectos psicológicos en esta obra; me limitaré a analizar los comportamientos menos caballerescos y heroicos de su protagonista.

No quiero negar la imagen heroica de Palmerín en la obra, pero sí que se destacan algunas debilidades que lo humanizan. Vistas estas debilidades en su

andantes pueden ser arrastrados por la pasión. El caso de Galaz (Galahad, Galaad, etc.) es distinto, pues incluso se ha interpretado como símbolo de Cristo en una de las obras más hermosas de este mito, La búsqueda del Santo Grial; como afirma Alvar en el estudio introductorio a su traducción de esta obra: «El simbolismo queda claro en Galaz («Puro entre los puros»), cuya vida sigue la de Jesús: es esperado por todos desde hace siglos como el salvador que dará fin a las aventuras más extrañas» (1986: 11).

${ }^{2}$ Los estudios fundamentales sobre el ciclo de los Palmerines son los siguientes: los que acompañan a la edición de Di Stefano (1966), entre ellos destaca la monografía de Mancini (1966), que se reeditó en castellano unos años después (1970: 9-202); también se ha de destacar la excelente tesis doctoral de Marín Pina (1989); Di Stefano en colaboración con Daniela Pierucci ha publicado una nueva edición actualizada de la de la obra recientemente (2004), con un estudio introductorio de Marín Pina; esta última edición es la que utilizo para todas las citas del Palmerín de Olivia en el presente estudio.

${ }^{3}$ En relación a su autoría, se han barajado diversas posibilidades, Juan Augur de Trasmiera, Francisco Vázquez y Catalina Arias, pero no existen datos que corroboren de manera fehaciente este asunto. Mancini (1966) considera a Trasmiera como autor de esta obra y del Primaleón; Marín Pina (1991) ofrece nuevos datos sobre Francisco Vázquez y su madre, Catalina Arias, a la que, tal como ella constata, los historiadores locales de Ciudad Rodrigo atribuyen la obra; Ferrario de Orduna (2000 y 2005) parece inclinarse por una autoría conjunta en la que colaboraron un hombre y una mujer. 
conjunto, se percibe una cierta evolución no hacia una perfección ideal, sino hacia un aprendizaje de supervivencia. Palmerín de Olivia se presenta como un valeroso guerrero, un inteligente estratega, un magnífico caudillo militar, un amante fidelísimo y un leal caballero, como se evidencia en la mayoría de sus aventuras, pero estas mismas aventuras revelan que, como todo ser humano, Palmerín tiene sus flaquezas. Lilia Ferrario de Orduna señaló algunos comportamientos poco caballerescos en algunos personajes del Primaleón ${ }^{4}$, e indicó como originalidad que estos hechos no fueran abiertamente criticados por el narrador:

Aunque las situaciones de felonía en la literatura caballeresca son frecuentes, a mi entender, es original la impunidad con que este narrador protege a algunos personajes que carecen de responsabilidad y de sentido de culpa (Ferrario de Orduna, 2005: 729).

Como afirma Ferrario de Orduna, esta «impunidad» es un rasgo de originalidad en el Primaleón que - añado yo - también se da en el Palmerín de Olivia, originalidad que nos habla de cómo estas obras iniciales que están configurándose como piedras angulares del género caballeresco revelan una marcada heterogeneidad de modelos heroicos ${ }^{5}$. Estas diferencias no impidieron el éxito de Palmerín de Olivia, éxito que se comprueba en el número de reediciones ${ }^{6}$ y traducciones a distintas lenguas (incluyendo la versificación de Ludovico Dolce), así como en testimonios de la recepción de la época; Alonso Fuentes, en su Suma de Filosofía Natural (1547) mencionaba el caso de un lector empedernido de libros de caballerías que mostraba una especial predilección por el Palmerín de Olivia ${ }^{7}$. Y es bien sabido que en su Diálogo de la lengua Juan de Valdés elogiaba por su estilo esta obra junto con los textos de Montalvo.

\section{EL MIEDO DEL HÉROE}

La vinculación genérica del Palmerín con los textos amadisianos resulta evidente y así se percibía en la época. Por ello, sorprenden algunos rasgos de

\footnotetext{
${ }^{4}$ La investigadora menciona «las falsas actitudes de Belagriz, los fingimientos de Polendos hacia Leifida con tantas muertes innecesarias como resultado, las malévolas y crueles simulaciones de Lecefín también con sangrientas secuelas, hasta la increíble injusticia de Frisol» (2005: 728).

${ }^{5}$ Mayor incluso que la estudiada por Amezcua (1984).

${ }^{6}$ Para cualquier dato relativo a la transmisión impresa de los libros de caballerías, la lectura obligatoria es Lucía Megías (2000), y, concretamente en relación al Palmerín de Olivia en esta monografía, las pp. 384 y 387.

${ }^{7}$ Tomo el dato de Thomas (1952: 69-70). El investigador también recuerda la buena opinión que W. E. Purser tenía de esta obra, que considera uno de los libros de caballerías más divertidos (ibid.).
} 
su protagonista que lo diferencian de Amadís; por ejemplo, el miedo llega a apoderarse de Palmerín en más de una ocasión, que siente tal pavor que incluso llega a huir del peligro, algo impensable en su modelo amadisiano.

Una de las primeras aventuras palmerinianas, cuando el héroe se encuentra en esa fase inicial de adquirir fama en el mundo caballeresco, sucede en el Imperio de Constantinopla, en un momento en el que aún ignora que su linaje se encuentra allí. Se trata de la lucha contra la temible serpiente que protege la fuente cuya agua mágica podrá sanar al tullido Primaleón, Emperador de Constantinopla y, aunque el héroe no lo sabe, su abuelo. La importancia de esta aventura radica en que es la primera ocasión en que su valor se pone al servicio de su propio linaje. El caballero, cuando se entera de la enfermedad del emperador, no duda en acometer la aventura, pero al contemplar la horrorosa serpiente su coraje desaparece de un plumazo: «Palmerín estovo esperando qué faría e no tuvo tanto coraçón que no huviese gran miedo» (41). El héroe flaquea y duda de estar capacitado para enfrentarse a tan horrible monstruo, cuya cueva estaba sembrada de huesos de sus víctimas «así de hombre como de bestias que la sierpe había despedazado e comido» (ibid.). En esta ocasión, las dudas y miedos del caballero minan su determinación y valor: cada vez que se anima a pelear contra la sierpe el temor le obliga a regresar («Palmerín no sabía cómo la acometer e muchas vezes salió por yr a ella e tantas vezes se tornava, tanto que de sí mesmo tomó vergüença», ibid.). Todo esto sucede mientras el héroe se encuentra entre unas matas, escondido y lleno de miedo.

Su temor no se debe a la falta de experiencia, sino a lo temible del monstruo al que se enfrenta. No creo que se pretendiera ofrecer una imagen anticaballeresca del héroe, sino humanizarlo al tiempo que se insistía en la fiereza de la bestia a la que debía derrotar. El temor del protagonista paradójicamente aumenta el valor de su hazaña; cuando finalmente reúne el coraje necesario para luchar y acabar con la serpiente, el caballero no puede por menos que sorprenderse ante su propio triunfo: «quando lo vido tan grande él se maravillava de sí mesmo cómo la havía podido matar» (43). De esta manera, no creo que pueda considerarse un acto de falsa modestia cuando poco después atribuye su gesta a Dios, sino a una verdadera convicción de que la divinidad lo había auxiliado en ese trance: «la sierpe Dios la mató, que yo no tuviera poder» (ibid.).

Sin ofrecer detalles, Henry Thomas mencionó que esta aventura recuerda a la lucha contra el Endriago en el Amadís de Gaula (1952: 69); en mi opinión, esas similitudes consisten fundamentalmente en las consecuencias físicas de la lucha en el caballero, que pierde mucha sangre, piensa que va a morir y se desmaya; además, de igual manera que hizo Amadís, Palmerín no olvida dar las gracias a Dios por la victoria ${ }^{8}$. Por otra parte, al igual que en el libro

\footnotetext{
${ }^{8}$ Sobre este episodio de la obra de Montalvo y sus derivaciones en otros libros de caballerías, vid. Martín Romero (2010).
} 
de Montalvo, también aquí el episodio cuenta con un valor estructural determinado. Si, como analizó Cacho Blecua, la aventura del Endriago suponía la presentación del héroe en la corte del Emperador de Constantinopla, el personaje de estatus más alto de toda la novela y, por tanto, para el que se requiere una hazaña especialmente señalada ${ }^{9}$, esta aventura de Palmerín es su presentación en la corte de su progenitor (aunque el héroe aún no lo sabe).

Pero los paralelismos se detienen ahí, mientras que las diferencias, fundamentalmente psicológicas, son más evidentes, pues si nada ni nadie puede disuadir a Amadís de enfrentarse al que es considerado un verdadero diablo y una muerte segura, Palmerín revela unos temores que, si por una parte lo alejan del modelo ideal de caballero, por otra lo humanizan ante los ojos de sus lectores. Las dudas y temores de Palmerín contrastan con la confianza —ya señalada por Cacho Blecua (1979: 282) — con que Amadís se enfrenta al monstruo.

Como he dicho, el miedo que siente Palmerín no se debe a la falta de experiencia. Tiempo después, este caballero ha de enfrentarse a una aventura en la que la magia juega en su contra. Ha de montarse en una barca que lo llevará a un territorio encantado ${ }^{10}$, pero durante la corta travesía acuática los hechizos le hacen pasar un mal rato:

E como Palmerín esto fizo, desató la barca e metióse dentro e tomó un remo que en ella estava e començó de remar e yrse por el río. Mas allí fue la cuyta, que las ondas d'él se començaron a alçar muy altas; por grande fuerça que Palmerín tenía, no se podía valer, porque un pescado muy grande de estraña manera le quería trastornar la barca, y él se vido en la mayor cuyta que jamás se vido, que quando mató a la gran sierpe en la montaña Artifaria no tuvo tanto miedo ni peligro (137).

No es casual la alusión a esta hazaña, ya que en ella se había aludido de forma explícita al terror que había sentido el héroe. Aquí se vuelve a mencionar su miedo (aún mayor que en aquella ocasión); el autor no quiere que el lector pase por alto este detalle y más adelante insiste de nuevo en el pánico que siente: «Allí no le valía a Palmerín su gran fuerça ni coraçón, que mucho desmayava, e si Dios no le acorrera en esforçalle muriera de espanto, tan grande tormenta fazía el río con él»(ibid.). La Divinidad le infunde el

\footnotetext{
${ }^{9}$ Cacho Blecua afirma: «El emperador es el personaje de más elevado rango social del relato y las credenciales de Amadís no pueden ir avaladas por su fama, sino tras haber acometido algún hecho especialísimo, clímax guerrero de su larga peregrinación. Como estructura novelesca y no como estructura simbólica exclusivamente, el episodio del Endriago tiene su marco adecuado» (1979: 278).

${ }^{10}$ Sobre la aventura de la nave encantada, vid. Guijarro Ceballos (2007). A pesar de que la aventura palmeriniana a la que me refiero dista de cumplir todos los rasgos propuestos (por ejemplo, el héroe ha de remar, ya que no se mueve por sí misma), el carácter mágico de todo el episodio hace difícil que no se vincule de alguna manera con este tipo de aventuras que parodió Cervantes en el Quijote.
} 
valor necesario para continuar; el caballero suelta la espada para poder remar más velozmente a dos manos y llegar cuanto antes a tierra; en cuanto desembarca, el héroe se arrodilla y da gracias a Dios por haberlo salvado; aunque aún ha de enfrentarse a otros peligros para concluir su aventura, ninguno le hace sentir tanto miedo. La aventura de la sierpe se narraba en el capítulo XVII, este de la barca encantada, en el LXIII; el tiempo, la experiencia y los logros alcanzados entre estos dos momentos vitales no le impiden seguir sintiendo un miedo racional y lógico, pero le ayudan a ser capaz de superarlo, de actuar de manera caballeresca a pesar de sentir esos temores.

Palmerín, frente a Amadís, siente miedo, un miedo que llega a avergonzarlo. Su reacción es intentar vencerlo, normalmente hablándose a sí mismo, reprochándose su cobardía. En el episodio de la sierpe así lo hizo ${ }^{11} \mathrm{y}$, aunque no recurre a esto en la aventura de la barca, sí que lo hace en otras ocasiones. Así, cuando se entera de que en Gante se produce una matanza a diario a manos de un caballero protegido por un encantamiento, decide acabar con esa tragedia. Cuando llega a dicha ciudad y ha de enfrentarse a este adversario, es consciente del enorme peligro; se detiene un momento a reunir valor y, para ello, se habla a sí mismo en los siguientes términos:

Palmerín, tú no dudes en acometer este fecho, que si verdad es la gracia que las fadas me dieron en la montaña Artifaria, ningún encantamiento me puede nuzir. Si muriere, moriré por librar a mi señora e será mi muerte bien empleada (69).

Los efectos anímicos de estas reflexiones para darse ánimos se dejan sentir inmediatamente ( $« \mathrm{E}$ crescióle el ardimiento con este pensamiento tanto que ya se quisiera ver en la batalla», ibid.). Pero en su reflexión se observa cómo el caballero analiza la situación en todos los detalles: si la magia protege a su enemigo, lo mismo le sucede a él, se trata de un combate en igualdad de condiciones; de ahí que contemple la posibilidad de morir, y lo acepte, pues se trata de defender nada más y nada menos que a su amada, Polinarda, a la que, por cierto, todavía no ha visto en persona, sino tan sólo en sueños.

Por otra parte, Palmerín se individualiza por contemplar la posibilidad de no superar las pruebas a las que se enfrenta. Los momentos de pánico que hemos visto son buena muestra de ello, pero en otras ocasiones se afirma de forma explícita que el héroe no cree que pueda rematar una aventura con éxito. En el capítulo XXIII, se narra cómo durante su errancia se encuentra con una doncella que porta una arquilla con una espada que sólo podrá sacar el mejor

${ }^{11}$ Tras intentar enfrentarse a la sierpe en varias ocasiones y regresar lleno de miedo antes de que la bestia lo viera, se avergüenza y se dice a sí mismo «Palmerín, no es éste el esfuerço que tenías delante de Florendos e de la Infanta, su hermana»(41). Este reproche a sí mismo se carga de sentido a los ojos del lector, que sabe que Florendos es el padre del héroe y que, por tanto, la infanta, hermana de Florendos, es su tía. Aunque el caballero lo ignora, se mencionan razones familiares que refuerzan la necesidad de acometer la aventura. 
caballero $^{12}$. Pues bien, Palmerín analiza la situación y se plantea que quizá no lo consiga:

Palmerín estovo pensando si provaría de sacarla, porque si no lo fiziesse le sería desonrra. E a la fin acordó de ponerse con otros muchos cavalleros de gran cuento que la havía provado e no la havían acabado, según la donzella dexía (54).

De ahí que cuando la doncella lo anima, él afirme «aunque me será escusado, como a los otros» (55), se refiere a quienes lo han intentado sin éxito antes que él. Es curioso que dé por sentado su fracaso antes de intentar la prueba. El héroe vuelve a demostrar sus dudas en otra de las aventuras, en concreto en la del Castillo de los Diez Padrones; antes de llegar a enfrentarse con diez caballeros que lo guardan, ha de tratar de extraer una espada de un padrón, prueba de origen artúrico en la que Palmerín no logra el éxito, de manera que duda de poder superar la prueba mágica: «E mucho dudó en su coraçón de no entrar en el castillo quando no pudo sacar la espada» (289), eso sí, no por ello deja de acometer la aventura y, astutamente, calla sus recelos («mas no lo dio a entender», ibid.).

Quiero insistir en que estos momentos de falta de coraje no intentan desdorar - aunque sí matizar- la imagen heroica de Palmerín; su actitud general ante el peligro es de una valentía extraordinaria. Si cabe, el hecho de que el personaje sea capaz de percibir el riesgo que corre su vida no hace sino enaltecer aún más el valor que requiere acometer un hecho en el que se piensa morir. El caballero no es osado porque ignore el peligro, lo es porque, a pesar de conocer el peligro, se enfrenta a él. Corriendo el tiempo, esta corriente más humana del héroe desembocará en Rosián de Castilla, impresa en Lisboa en 1586, cuyo protagonista, bien distinto del arquetipo heroico, es un modelo de aprendizaje vital y humano, que no duda en huir en varias ocasiones para salvar la vida ${ }^{13}$. La comparación entre Palmerín y Rosián revela las enormes diferencias de carácter entre ambos: lo que en el primero se contempla como una valoración de los riesgos y una reacción humana inevitable incluso en el corazón más valiente, en el segundo se aleja claramente de toda visión idealista.

${ }^{12}$ En realidad, Palmerín encuentra a la doncella, que pide ayuda porque dos caballeros le habían robado la arquilla con la espada. Le explica que se trata de una prueba mágica que sólo ha de probar quien le prometa un don en blanco. Ante la petición de ayuda de la dama, el héroe busca a los caballeros, acaba con ellos y devuelve la arquilla a la dama. Rápidamente su compañero Tolomé prueba sin éxito a abrir la arquilla; frente a esto, Palmerín reflexiona antes de actuar, ¿rasgo de mesura y sensatez? A juzgar por otras inseguridades del caballero quizá se pueda interpretar como lógicas dudas de poder realizar lo que ningún ser humano antes ha podido, al fin y al cabo un actitud bien distinta de la heroicidad de Amadís.

${ }^{13}$ Rosián huye en diversos momentos de la novela: el cap. XI de la primera parte y los caps. I, II y XVI de la segunda parte. Las citas de esta obra en el presente estudio proceden de Romero de Cepeda (1979). La obra ha sido analizada por Sales Dasí (2001). Por su parte, Romero Tabares (2001) analizó la figura femenina en esta. 


\section{LAS MENTIRAS Y ENGAÑOS DEL HÉROE}

Otros comportamientos de Palmerín también sorprenden en quien se presenta como flor de la caballería andante. El héroe, por ejemplo, no duda en recurrir a la mentira para soslayar diversos obstáculos que se le presentan, sea para salvar su vida, sea para detener los avances eróticos de diversas damas y así permanecer fiel a su amada Polinarda. Es cierto que prácticamente siempre que utiliza la mentira lo hace en territorio infiel; se deja entrever que un cristiano no debe sinceridad a quienes no profesan su fe, y ello a pesar de que el comportamiento musulmán se refleja en la obra siguiendo unos patrones caballerescos idénticos a los cristianos ${ }^{14}$.

Durante su errancia, Palmerín se ve separado de sus amigos en las tierras del Soldán de Babilonia. Allí es consciente del peligro en que se encuentra $\mathrm{y}$, por ello, finge ser mudo para evitar que se le reconozca por su forma de hablar ${ }^{15}$. Pasado el tiempo, una vez ha aprendido perfectamente el idioma de aquella tierra, comete el error de pronunciar unas palabras que, lejos de revelar su mentira, son tomadas como un milagro. Lo hace en un momento de indignación cuando la hija del Soldán es acusada por un arrogante caballero. Teniendo en cuenta que Palmerín habla para defender a la doncella, no es ilógico que rápidamente los musulmanes piensen que se ha obrado un milagro, de otra manera la dama perdería al único que tiene el valor de defenderla en ese trance. El héroe se justifica comentando que había perdido el habla a causa de un gran mal, como si de un trauma se tratara. En puridad, Palmerín aquí no miente, pues el mal de haberse perdido en esas tierras le forzó a fingir la mudez, pero es consciente de que sus interlocutores lo interpretarán de otra manera. Se trata de un caso más de verdad ambigua, frecuente en textos caballerescos tanto españoles como de otras literaturas románicas (Martín Romero, 2008b $)^{16}$. Pero el haberse fingido mudo no puede ser considerado sino como una mentira consciente. Cuando la hija del Soldán, irremediablemente enamorada del caballero, le declara abiertamente su amor, éste no puede rechazarla, ya que su vida correría peligro, y por ello decide mentirle, diciendo que él también la ama y que sólo le pide que espere a que consiga la fama y dignidad suficientes para ser merecedor de su mano:

${ }^{14}$ Marín Pina afirma sobre las cortes infieles que se reflejan como idénticas a las cristianas, con la única diferencia de la religión (2004: XXII). Es más, los musulmanes se presentan en esta obra como caballeros a quienes también les gusta dedicarse a justas, torneos y tienen un comportamiento cortesano idéntico al que se espera de un caballero cristiano, tal como sucede en el Abencerraje.

${ }^{15}$ Sobre la importancia de hablar lenguas extranjeras en la errancia caballeresca, vid. Campos García Rojas (2005).

${ }^{16}$ Esta doble verdad es en esencia distinta de la disimulación y simulación, cuyos valores pragmáticos habían sido propugnados en diversos tratados de cortesía y cortesanía del Renacimiento, como ha estudiado Laspalas (2006); no obstante, consiste en una estratagema orientada a los mismos fines que aquellos. 
Yo tengo razón de amaros e servíos más que a ninguna donzella que hay en el mundo e ansí lo faré; (...) yo entiendo de fazer tales servicios a vuestro padre qu'él aya por bien, quando viniere, de fazerme esta merced, rogándoselo vos (184).

Aunque le confiesa algunas verdades - su nombre, el hecho de que no ha conocido a su padre-, le miente con descaro (para evitar que descubriera que no era musulmán) cuando le cuenta que creció en Persia: «E no sé qué más vos diga de mi fazienda, salvo que me crié a las partes de Persia. —Esto dixo Palmerín porque Alchidiana no pensasse qu'era cristiano» (184). Palmerín no se siente culpable por haber mentido, por su falta de sinceridad, pero sí por el hecho de haber faltado, aunque obligado por las circunstancias, a su fidelidad hacia Polinarda. Se siente como si hubiera negado su amor y, como un nuevo San Pedro, llora su pecado ${ }^{17}$. Vuelve a mentir a Alchidiana cuando intercede por su amigo Olorique ante ella. La dama, que no comprende por qué su amado intenta que acepte el amor de otro caballero, le reprocha su actitud amargamente, y ante esto, Palmerín miente de nuevo y le dice que no pretendía tal cosa, sino tan sólo aconsejarle que honrara — no que amara- a Olorique. Llega a afirmar con cierto descaro: «Mucho sería yo de poco seso si yo quisiese para otro la mi buen andança» (197-198); e incluso le pide que lo crea: «Pídovos por merced que tengáys por ciertas las palabras que vos tengo dichas y ningún temor tenga vuestro coraçón de mi lealtad» $(198)^{18}$. Este tipo de mentiras recuerdan a las del caballero Zifar con su segunda esposa, la hija del rey de Mentón, cuando le cuenta que ha hecho voto de castidad durante un determinado período de tiempo con el fin de evitar consumar el matrimonio, lo que le permitirá no ser infiel a su primera esposa, Grima.

En otra ocasión, y de nuevo en territorio musulmán, Palmerín recurre a la mentira. En las tierras del Gran Turco encuentra a Agriola casada contra su voluntad con éste, que no ha podido consumar el matrimonio ya que la dama cuenta con la protección de un hechizo. El caballero finge ante el Gran Turco ser el hermano de esta dama y le promete — sin intención de cumplirlo- convencer a Agriola de que acepte sus avances eróticos, engaño que le permitirá gozar del favor de este gran señor musulmán y así preparar la huida.

En otras ocasiones, la mentira resulta del todo gratuita. Así al comienzo de sus aventuras Palmerín llega al Imperio de Constantinopla, donde un enano (Urbanil, que se convertirá en su escudero) le habla de la enfermedad del

17 «parecióle que delante de sí tenía a su señora que se quexava d'él por lo dicho: aunque en el coraçón no lo tuviesse, la negava. Y ansí estuvo todo aquel día muy cuydoso rogando a su señora con lágrimas que lo perdonasse, que jamás la herraría» (184).

${ }^{18}$ A pesar de las diferencias, estas mentiras ante los avances eróticos de una reina bien pudieron servir de inspiración a Feliciano de Silva, años después, a la hora de narrar las aventuras de Florisel de Niquea y de la reina Sidonia, aunque de forma inversa, pues Florisel, bajo la falsa personalidad de Moraizel, casa con Sidonia para salvar a su amigo Falanges de Astra; no obstante, en ambos casos los héroes mienten abiertamente sobre sus sentimientos por puro pragmatismo. 
emperador Primaleón, y le informa de que su única salvación es beber el agua de una fuente encantada custodiada por una temible serpiente (se trata de la horrible sierpe de la montaña Artifaria, la que, como dije, hace temblar a nuestro héroe). En este instante en que acaba de conocer la noticia, decide acometer el hecho (ignorando aún el miedo que ha de pasar). Lo curioso es que en su respuesta, y sin que sepamos muy bien por qué, afirma que ya conocía todo el asunto - del que acaba de enterarse, insisto- y que de hecho el motivo de su viaje no era otro que enfrentarse a la sierpe para conseguir el agua que sanará al emperador: «Amigo, muy bien me has sabido contar estas nuevas. E yo ya havía oýdo parte d'ellas y esto me fizo venir acá, porque me conviene de provar lo que los otros han provado» (36). Podríamos pensar en la posibilidad de que Palmerín supiera algo relativo a la enfermedad del emperador Primaleón, del agua mágica y de la Sierpe que protegía la fuente, aunque no se nos hubiera contado en la historia, pero acabamos de presenciar un largo diálogo en que el héroe no paraba de hacer preguntas a Urbanil, demostrando que realmente no conocía este asunto y que las noticias que le da el enano son las primeras que tiene al respecto.

En cualquier caso, la insinceridad no parece ser considerada una falta demasiado grave, si bien en el Amadís de Gaula y en otras obras, se recurría, antes que a la mentira, a la verdad ambigua, aquella que los interlocutores interpretan de forma inadecuada y le permite al caballero ocultar la realidad ${ }^{19}$. No obstante, hay que tener en cuenta que en algunos tratados sobre caballería, si bien se rechaza la mentira, se defiende su uso por motivos prácticos, esto es, por los males que puede evitar mentir. Así, Alonso de Cartagena tras exponer que todo caballero debe evitar la falsedad, justifica algunos casos:

Otrosí tenían por bien que se guardasen de mentir en sus palabras, fueras ende en aquellas cosas que se oviese a tonar la mentira en algún grand bien, así desviando daño que podría acaescer si non mitiesen, e otrosí trayendo alguna pro, metiendo asosegamiento con los omnes que fuesen movidos a fazer algún grand mal, o poniendo paz o acuerdo entre aquellos que se desamasen, o en otra cosa que por aquella mentira se quitase mal e traxiesen bien (Cartagena, 1995: 40-41).

Esta teoría pre-maquiavélica del fin como justificación de los medios ${ }^{20}$ en el caso de la mentira quizá pueda exculpar algunas de las este héroe, pero los casos citados por Cartagena no parecen coincidir con el provecho personal del caballero, que es lo que mueve a mentir en muchas ocasiones a Palmerín.

\footnotetext{
${ }^{19}$ Otras virtudes se valoraban más que la sinceridad en el caballero vid. Martín Romero (2008b: 505).

${ }^{20}$ Vid. los comentarios de Viña Lista en Cartagena (1995: 41, nota 184). No obstante, sigue siendo una actitud muy medieval, ya que en mi opinión parece apoyarse aún en la teoría de Santo Tomás de Aquino más que los tratados de cortesía del Renacimiento analizados por Laspalas (2006).
} 


\section{MALTRATO A LA MUJER}

Más extraño aún resulta el comportamiento de Palmerín con algunas doncellas. Como afirma Bueno Serrano, en la literatura caballeresca la «violencia asociada a enanos, doncellas y dueñas anónimas de los textos iniciales incorpora esta función legitimadora, convierte a los caballeros en responsables de controlar las agresiones y en figuras imprescindibles para su resolución» (2005: 443). Efectivamente, entre las obligaciones de todo caballero está la defensa de las «doncellas menesterosas», enmendar las injusticias que se haya cometido contra ellas y vengar las ofensas que hayan sufrido. Pues bien, en este mundo en el que el caballero andante se erige como valedor y defensor del sexo débil, sorprenden de manera extraordinaria ciertas actitudes de Palmerín hacia algunas damas. Por ejemplo, cuando su amigo Trineo, príncipe de Alemania, se enamora perdidamente de Agriola, hija del rey de Inglaterra, Palmerín le reprocha su comportamiento («iPor Dios, que yo pensé de jamás veros con tan poco coraçón!», 152) y proclama que la doncella no vale tanto como él: «Agriola es la que aquí más gana; no sé yo por qué la tenéys en tanto» (152).

Por si fuera poco, cuando anteriormente el héroe había intentado convencer a esta dama de que aceptara el amor de Trineo, no había dudado en recurrir a la coacción: le dice a la doncella que, en caso de que rechace el amor de Trineo, casará con otro peor y entonces lamentará la oportunidad perdida («vos casaros eys con el Duque de Gález, vasallo de vuestro padre; e a él no faltará la más alta donzella de todas las del mundo, e quando vos lo supierdes conosceréys el bien que perdistes», 152); además, amenaza con acudir con todo el ejército del padre de éste, el Emperador de Alemania, para atacar al rey de Inglaterra, mientras que con su matrimonio se podría alcanzar la paz entre esos territorios:

que yo vos prometo que, en llegando Alemaña, Trineo faga venir todas sus gentes e tornaremos al reyno de Inglaterra e no vos podía escapar que no sea todo destruydo; e todos los males que se fizieran yrán sobre vos. E si vos quisiésedes, sería al contrario: pondríades paz entre el Emperador e vuestro padre, y escusaríedes muchas muertes de cavalleros (152).

Se ha de destacar el tono amenazante, no precisamente conciliatorio, del héroe, que literalmente coacciona a la dama para que acepte la propuesta de matrimonio de Trineo. Por si hubiera dudas, el autor señala la actitud del caballero: «E como esto dixo, callóse e mostró grande enojo», ibid.). Ese «grande enojo», sus amenazas, e incluso la negativa a debatir el asunto y dejarlo en manos de Agriola («Vos fazé lo que quisierdes, que yo no entiendo de fablar más en este fecho», ibid.) transmiten un proceder en absoluto caballeroso por parte de Palmerín, que se aleja en este momento del comportamiento cortesano y comedido esperable en un héroe de un libro de caballerías, entendido como el derivado del modelo amadisiano. 
Pero más violento aún es su comportamiento con una dama llamada Valerica. Ésta había despertado el amor de Varván, que, al no verse correspondido, había caído en una depresión y vivía como un salvaje (siguiendo los modelos de la penitencia de amor que ha estudiado Aguilar Perdomo, 2001). Palmerín encuentra a Varván haciendo tan triste vida y, emocionado, decide interceder por él. Descubre que Valerica en realidad ama - y se entrega - a otro caballero, al que Palmerín mata sin más y, tras ello, secuestra a la dama con la intención de entregarla a Varván. Inicialmente ella piensa que es su amante, y le pide que no la aparte de la casa de su padre. Su incomprensión y dolor van en aumento, pues no recibe respuesta del que piensa que es su amigo. Cuando Palmerín se descubre, el horror de la dama es enorme ${ }^{21}$; él le cuenta con toda frialdad, entre risas, que va a llevarla al lado de Varván y, para colmo, que acaba de matar a su amante ${ }^{22}$. Durante el viaje encuentran a otro caballero al que la dama pide socorro ( Ay cavallero, doleos de mí, que me lleva forçada este mal caballero», 142), y éste, cumpliendo las expectativas, intenta liberarla, pero Palmerín lo derrota fácilmente y sigue su camino sin atender a las quejas y sollozos de la dama a la que lleva forzada. Este lance - tan frecuente en los textos caballerescos - presenta la singularidad de que es el protagonista - y no el antagonista - quien lleva a una dama contra su voluntad. Por otra parte, aunque cuando llegan a la cueva Varván le suplica a Palmerín que libere a Valerica, éste se niega y recurre una vez más a las amenazas para conseguir sus fines:

Por Dios, Valerica, yo creo que en todo el mundo no hay donzella más cruel y desleal que vos. Sabed que si no fazéys luego lo que vos ruego e de buena voluntad, que por vuestro mal me conos[ç]istes: yo vos tornaré a casa de vuestro padre e le diré tales cosas que a vos os pese.

Estas palabras presentan un tono de amenaza si cabe mayor que las que utilizó con Agriola en una situación relativamente semejante. Y de nuevo Palmerín aprecia más el valor del caballero amante que el de la dama amada, aunque aquí, fuerza es reconocerlo, con más motivo: «Él es gran loco en fazello, que vos no lo merescíades» (142). La dama se ve obligada a aceptar el amor de Varván ante el enojo que muestra Palmerín y ante la posibilidad de que éste descubra sus amores ilícitos con el fallecido caballero ${ }^{23}$.

${ }^{21}$ «-Ay captiva, cómo soy burlada!, que mayor es mi mal de lo que yo pensava, qu'este cavallero que me trae yo no lo conosco. Palmerín se rió (...)» (142).

${ }^{22}$ Palmerín no se conmueve en ningún momento ante el dolor de la dama, es más, parece divertirse a su costa: «iAy malandante de mí — dixo la donzella—, que cada vez se acrecienta más mi malandanza. ¡En poder de Varván el covarde tengo yo de yr! ¡Más querría ser muerta que verlo de mis ojos! ¡Malaventurado seáys que tanto mal me fezistes! —Yo no sé — dixo Palmerín - si Varván es covarde, mas el que vos teníades por amigo poco se defendió, que ligeramente lo maté. (...) La donzella pensó de ser muerta quando aquello oyó e no fazía sino maldezir a Palmerín» (142).

${ }^{23}$ «Valerica, que tan ayrado lo vido, ovo gran miedo d'él e pensó que descobriría toda su fazienda» (142). 
La violencia de Palmerín parece implicar un rechazo a la obediencia y sumisión del amante propios del amor cortés que regían el sentimiento amoroso en el Amadís ${ }^{24}$. Claro está, muy distinta es su actitud hacia su propia amada, historia de amor más cercana a los modelos amadisianos ${ }^{25}$. En la historia de Varván y Valerica se puede vislumbrar una cierta parodia del amor cortés, del matrimonio secreto y de la penitencia de amor, en frases como ésta en la que, una vez la dama acepta resignada su fortuna, accede a obedecer al héroe: «Palmerín fue ledo e tomólos luego las manos e desposólos tan bien como si fuera clérigo» $(144)^{26}$. Inmediatamente después, como si hubiera logrado una gran hazaña, y quizá para dejarles cierta intimidad, afirma tener sueño y se echa a dormir: «E como esto fizo, dixo que quería dormir, que avía mucho menester; e echóse encima de la cama e dormió gran pieça» (144).

En mi opinión, a lo largo de todo el episodio se respira un cierto aire paródico que continúa hasta el final. La muerte del amante de Valerica provoca que los hermanos del fallecido ataquen al padre de la dama, asunto del que Palmerín se desentiende sin importarle lo más mínimo. De esta manera, el padre de Valerica sufre tanto la pérdida de su hija (que permanecerá tres meses en la cueva con Varván) como el ataque de los hermanos del amante de la dama, y ambos males han sido causados por Palmerín, que se desvía conscientemente del camino para no tener que luchar en defensa del atribulado padre:

E allí supo nuevas como dos hermanos del cavallero amigo de Valerica, qu'él avía muerto, avían venido a cercar a su padre e demandávanle su muerte e avía entr'ellos grande discordia. Palmerín dexó aquel camino e tomó otro por no aver enojo con ellos (...) (144) ${ }^{27}$.

\footnotetext{
${ }^{24}$ Sobre los comportamientos amorosos y las filosofías del amor en los libros de caballerías, vid. Martín Romero (2009).

${ }^{25}$ Aunque, dicho sea de paso, el primer encuentro amoroso de los amantes es inverso al de Amadís y Oriana; en la obra de Montalvo se menciona la timidez del caballero y la gracia de la dama: «assí que se puede bien dezir que en aquella verde yerva, encima de aquel manto, más por la gracia y comedimiento de Oriana, que no por la desmboltura ni osadía de Amadís, fue hecha dueña la más hermosa donzella del mundo» (Rodríguez de Montalvo, 1991: I, 574); frente a este héroe tan tímido que casi no puede mirar a su dama, en el Palmerín sucede lo contrario: «Palmerín entró dentro e tomó a Polinarda en sus braços e sentósse con ella en un estrado e sin más le demandar licencia cumplió lo que por él era desseado, que Polinarda lo amava con tan ferviente amor que no se supo defender a cosa qu'él quisiese fazer ni paró mientes en cosa que venir le pudiesse, mas antes quedó muy contenta de lo fecho» (108). Este comportamiento ya implica un desvío claro del modelo propuesto por Amadís y resulta más humano (aunque sin llegar a los extremos rijosos de don Galaor), pero también menos considerado con la dama.

${ }^{26}$ Es bien conocido el estudio de Ruiz de Conde (1948), de referencia sobre el matrimonio secreto. Esta autora analiza el Libro del caballero Zifar, Tirant lo Blanch, Amadís de Gaula y —el único del ciclo palmeriniano - el Palmerín de Inglaterra (al que dedica las pp. 231-283).

${ }^{27}$ Es cierto que es un motivo folclórico recogido en el índice de Stith-Thompson, pero aquí, dadas todas las circunstancias que rodean este desvío, resulta difícil no intuir un aire paródico del comportamiento que ha de tener todo caballero.
} 
Aunque el narrador advierte que finalmente los amantes vivieron felices juntos y que el padre de la dama aceptó su unión, la violencia de Palmerín es innegable. En cualquier caso, estos episodios suponen la excepción en la trayectoria caballeresca del héroe, que normalmente cumple con sus obligaciones caballerescas al ayudar a las dueñas y doncellas menesterosas que se encuentra en su camino: lucha contra gigantes que han raptado damas y que les han usurpado sus posesiones (el caso de Esmerinda), defiende el buen nombre de aquellas que han sido calumniadas (Cardonia), se enfrenta a quienes han robado a alguna de ellas (la citada doncella de la arquilla de la espada), etc. Por eso mismo, porque su comportamiento general es el esperable en un caballero, estas manchas en su expediente resultan más llamativas.

\section{LA TRAYECTORIA AMOROSA DE PALMERÍN: ENTRE AMADÍS Y GALAOR}

También la peripecia amorosa de Palmerín se desvía de los pasos de Amadís. El héroe se enamora perdidamente de una dama a la que ve en sueños y cuya identidad ignora; en realidad, como se sabrá posteriormente, es un trasunto onírico de Polinarda, hija del Emperador de Alemania.

Este amor ex visu, pero en sueños, predestina al caballero; no obstante, su trayectoria sentimental se verá complicada cuando conozca a Laurena, hija del Duque de Duraço, cuya hermosura confunde al caballero. Inicialmente considera que ella puede ser la misteriosa mujer de sus sueños y entabla una comunicación amorosa con ella sirviéndose de su enano Urbanil como mensajero. Cuando se entera del nombre de la doncella comienza a dudar, porque no coincide con el que en cierta ocasión oyó que era el de la dama a la que estaba predestinado. Todas estas dudas se disipan ante la presencia de Laurena; el autor es muy sutil a la hora de hacernos ver cómo el héroe se ve dividido entre su ardor juvenil y su destino, disyuntiva en la que está a punto de ganar su fogosidad, hasta el punto de que el caballero exclama: «¡Ay cativo!, ¿qué haré, que mucho me ha vencido la fermosura d'esta donzella? No sé si crea los sueños, que son vanidades» (51). Tan cegado está Palmerín por esta pasión que, para que siga su destino, la misteriosa dama vuelve a aparecer en sueños, pero no en los del caballero, sino en los de su escudero Urbanil, que le cuenta lo sucedido al héroe de manera que éste decide abandonar apresuradamente Duraço (y sus tentaciones), dejando a la desconsolada Laurena, que no entiende la súbita mudanza de su amado.

Este juvenil error de Palmerín, no obstante, no impide que supere tiempo después una prueba mágica — la corona de Manarix — destinada a aquel caballero que siempre hubiera sido fiel a su amada. Eso sí, antes de probar la aventura, Palmerín se plantea si esos escarceos de juventud le impedirán re- 
matar la aventura con éxito ${ }^{28}$. Pero este éxito en una prueba que recuerda a la del Arco de los Leales Amadores en el Amadís no logra hacer olvidar que Palmerín fue capaz de confundirse de dama y estuvo a punto de dejarse llevar por la fogosidad olvidando su amor verdadero.

\section{EL HÉROE RENIEGA DE SU FE}

Pero sin duda el punto culminante de anti-heroísmo en la trayectoria vital de Palmerín es el momento en que decide entregarse a sus enemigos infieles antes que enfrentarse a ellos. El desarrollo del relato no deja de sorprender. Se trata de la primera aventura de Palmerín tras haber sido reconocido como hijo de Florendos y Griana, esto es, como heredero del trono del Imperio de Constantinopla. No obstante, el autor ha mantenido a su compañero Trineo, hermano de Polinarda, amada del héroe, perdido (en realidad convertido en perro por el encantamiento de Malfado, una nueva Circe). Claro está, Palmerín no puede abandonar al que será su futuro cuñado y, acompañado solamente por cinco caballeros, parte a la aventura, literalmente ya que, como no sabe dónde empezar a buscar, deja que la nave sea dirigida por los vientos, esto es, se abandona en las manos de la Providencia («por donde la ventura los guiasse», 253). El inicio del episodio resulta de lo más heroico, la euforia aventurera se deja sentir en el corazón de los jóvenes personajes:

E como todos seys eran mancebos e muy fermosos e loçanos de coraçón, que todos los más d'ellos amavan muy afincadamente, parecíales que podrían acometer qualquiera gran fecho (253).

Pero esta euforia dura poco, ya que se topan con una flota del Gran Turco, que iba «a correr tierra de cristianos» (ibid.). Y es aquí cuando la actitud de Palmerín sorprende, pues, en lugar de enfrentarse a los enemigos de su fe atendiendo a las expectativas del lector de los textos de Montalvo, propone algo bien distinto:

Nosotros no podemos escapar de ser presos d'ellos; conviénenos de sofrillo. Pues Dios ansí lo ha ordenado, quiça será para mayor bien nuestro, ya que más ha menester seso que ardimiento, que las cosas con que los hombres no pueden salir no las deven acometer (254).

Extraña filosofía en un heredero directo de los modelos amadisianos. Se ha de recordar cómo en el episodio del Endriago, el maestro Elisabad intentó convencer al héroe de que no luchara contra el monstruo con argumentos

\footnotetext{
28 «estaba pensando muy fieramente en su señora como él jamás la avía herrado sino en Duraço por amor de Laurena, e dezía en su coraçón que aquello no se avía de contar sino por yerro en no la conocer» (172).
} 
parecidos a los que utiliza Palmerín en esta ocasión («Y el maestro Elisabad, que como hombre de letras y de missa fuesse, mucho gelo estrañó, trayéndole a la memoria que las semejantes cosas seyendo fuera de la natura de los hombres, por no caer en omicida de sus ánimas se habían de dexar», II, 1138), argumento que Amadís rechaza de plano, pues aceptarlo implicaría negar la búsqueda de aventuras y el riesgo que ello conlleva ${ }^{29}$. Elisabad y Palmerín comparten un mismo pensamiento, un pensamiento opuesto al del héroe de los libros de Montalvo.

A mi entender se trata de una enmienda al modelo heroico propuesto por Amadís de Gaula ${ }^{30}$. No es de extrañar, por cierto, que también en esto coincidan Palmerín y Rosián de Castilla, ya que esta última obra supone una respuesta moralizante al género caballeresco. Romero de Cepeda justifica la huida de su héroe con argumentos parecidos a los de la obra palmeriniana: «porque gran temeridad es prouar las fuerças en las cosas impossibles, y no es valentía esperar ni acometer el peligro quando es euidente y claro y con desigual ventaja» (Romero de Cepeda 1979: 29); «no es flaqueza de ánimo huýr los peligros quando del esperallos se espera la muerte o pérdida de la honra» ${ }^{31}$ (Romero de Cepeda 1979: 63) e incluso un viejo ermitaño le indica que «locura es acometer el peligro cierto» (Romero de Cepeda 1979: 62). Es cierto que, como recuerda Rafael Beltrán, el debate entre el valor y la temeridad era frecuente en tratados bélicos medievales y áureos, pero en el mundo caballeresco, por lo menos en los modelos heroicos de los textos de Montalvo, sin duda valor y temeridad iban de la mano, como indica Amadís a Elisabad en el citado pasaje (Beltrán, 2004-2005: 49).

Como indicó Marín Pina, Palmerín se muestra ajeno al espíritu de cruzada, y se halla «dispuesto a salvar la vida antes que el alma» (2004: XII). El

${ }^{29}$ «Mas el Cavallero de la Verde Spada le respondió que si aquel inconveniente qu'él dezía tuviesse en la memoria, que escusado le fuera salir de su tierra para buscar las peligrosas aventuras», ibid.

${ }^{30}$ Como es bien sabido, la primera enmienda del modelo amadisiano vino de la mano del propio Rodríguez de Montalvo, que criticó la caballería bretona en favor de una caballería cruzada. Gili Gaya (1947) y Amezcua (1972). Pero aquí no se trata de ofrecer un nuevo modelo heroico para mejorarlo, sino todo lo contrario, consiste en rechazar el carácter arquetípico, perfecto, del héroe, de humanizarlo. El héroe deja de serlo para convertirse en un ser de carne y hueso.

${ }^{31}$ Aunque en realidad el autor quiere matizar lo que había expresado inmediatamente antes: «Pequeña ocasión han menester los hombres tímidos y couardes para fallescer de la virtud», es decir que huir en cualquier situación es propio de los cobardes, pero no huir de la muerte segura es propio de los locos. Se ha de observar que esta actitud supone, como en el caso del Palmerín, una enmienda a las propuestas heroicas de Amadís de Gaula, unas enmiendas todavía más evidentes que en el caso palmeriniano: la orientación moralista y la defensa del valor de la humildad explican que en la obra de Romero de Cepeda (1979) su protagonista sufra tantas humillaciones como posteriormente (con unos propósitos más humorísticos que moralistas) sufriría don Quijote de la Mancha en su locura. 
héroe, el único que habla el idioma de sus captores, se erige en portavoz y se encarga de ocultar el verdadero propósito de su viaje (buscar a sus compañeros) y miente: «ývamos a saber las cosas del mundo e a servir el mayor Señor que fallásemos, ora fuesse moro o cristiano» (254). Esta nueva mentira no es lo peor, ni tampoco que se entreguen al enemigo infiel sin luchar, lo verdaderamente sorprendente en un héroe caballeresco es que se entregue al caudillo de la flota del Gran Turco — llamado Olimael_, que les protege a cambio de que juren luchar a su lado en sus correrías en tierras cristianas: «Palmerín e los otros gelo juraron bien e lealmente» (254). Y efectivamente, ponen sus espadas al servicio de los infieles y se dedican a matar muchos de sus correligionarios para evitar su propia muerte. El autor narra estos lances señalando la ayuda que el héroe ofrece a los enemigos de la fe:

Allí fizieron Palmerín e sus compañeros cosas estrañas por onde Olimael los preció mucho. E la cibdad tomada, robáronla toda e cautivaron todos quantos cristianos en ella fallavan. E desde allí fueron por toda la costa de Albania adonde ellos fizieron muy grandes daños, e llevaron muchos cristianos cautivos (254).

El personaje es consciente de su pecado y se lamenta todavía más cuando llegan a las tierras del Duque de Duraço, padre de Laurena, su primer amor. Ni siquiera entonces se propone defender a los cristianos, aunque sí decide proteger a la dama de una posible deshonra a manos de los infieles. Resultan indicativas las palabras que el héroe dirige a sus compañeros en tierras de Duraço para comentarle su plan, en primer lugar, considera que no pueden hacer otra cosa que luchar contra los cristianos ayudando al ejército musulmán:

Ay señores, muy gran pesar tengo por venir a esta cibdad de Duraço, que muchas honrras he yo aquí recebido; e pues no podemos ál fazer sino yr contra los de nuestra ley por salvar nuestras vidas, ruégovos que punéys todos, si la villa s'entrare, de aver a las manos una donzella muy fermosa que es hija del Duque, porque no venga en poder d'estos malvados turcos que no la deshonrren (254-255).

En la lucha muere el padre de Laurena, pero Palmerín logra defender a ésta y pedírsela a Olimael para evitar que sea deshonrada. Cuando Laurena se entera de lo sucedido, no puede creer que Palmerín haya actuado de esa forma: « ¡Santa María, valme!, no puedo yo creer que el buen cavallero Palmerín se tornasse turco e fiziesse tanto mal en Duraço, pues él ya otra vez lo defendió» (255). Aunque el héroe no se ha convertido, sin embargo sí que ha hecho mal en esas tierras cristianas. El Duque de Ponte, uno de los compañeros de Palmerín, justifica la acción del héroe: «no vos maravilléys mucho, que la ventura faze a los hombres errar» (255). Aunque se atribuya la responsabilidad a la ventura (recordemos que se habían dejado llevar sin rumbo fijo abandonándose a la Providencia), no puede negar que se trata de un yerro. De hecho, Palmerín lamenta lo que está haciendo («qu'Él sabe muy bien quánto dolor tiene mi coraçón por lo fecho», 255). Cuando posteriormente el héroe se ve libre, no duda 
en intentar matar a todos los infieles que puede para redimirse, lo que demuestra su sentido de culpabilidad ${ }^{32}$. Es más, se ofrece a indemnizar a Laurena por los daños que ha sufrido y en los que él ha participado ${ }^{33}$.

\section{PALMERÍN, UN HÉROE HUMANO}

En definitiva, Palmerín de Olivia es un héroe caballeresco, pero al mismo tiempo se comporta de manera distinta, cuando no contraria, al modelo propuesto por Amadís y por Esplandián. Se detectan actitudes y comportamientos antiheroicos y anticortesanos en diversos ámbitos de su vida: en su caracterización como guerrero sorprende que pueda sentir miedo; en su vida cortesana llama la atención cómo llega a tratar a algunas doncellas (como Valerica o Agriola); incluso su actitud hacia la religión no está exenta de puntos dudosos, pues no tiene demasiados reparos en luchar contra los de su propia fe. Ningún aspecto vital de Palmerín resulta plenamente intachable.

En los últimos años han ido surgiendo interesantes estudios que han roto del todo la imagen del género caballeresco como uniforme y repetitivo. Además, se ha ido indagando en aquellos aspectos menos idealizados, aquellas otras realidades sociales —estudiadas por Lucía Megías y Sales Dasí (2002, 2005 y 2007) en el ámbito de los personajes secundarios- que revelan comportamientos menos virtuosos y cortesanos que los que la historiografía ha defendido tradicionalmente como únicos en el universo de los libros de caballerías. Lo verdaderamente curioso de Palmerín de Olivia consiste en que sea el mismísimo protagonista, el héroe, el que se comporte de una manera en ocasiones radicalmente opuesta a la de Amadís. A mi modo de ver se entrevé en Palmerín de Olivia no sólo una imitación de los libros de Garci Rodríguez de Montalvo, sino una respuesta a los textos de éste, cierto carácter sutil de parodia que sirve para poner en tela de juicio algunos comportamientos quizá considerados en exceso idealizados y, por ello, sobrehumanos. Esto puede explicar por qué Palmerín se aleja del modelo amadisiano y se acerca más, por el uso de argucias y ardides, al del Ulises homérico, no olvidemos que una de las aventuras de este caballero —el de la ínsula de Malfado- está claramente inspirada en el episodio de Circe en la Odisea ${ }^{34}$.

\footnotetext{
32 «E Palmerín, que sabía que aquéllos eran moros, no le dolía de matar en ellos mas antes pensava que enmendava el yerro que avía fecho en ayudar a los turcos contra los cristianos, de lo qual se fallava muy culpado; e allí puso todas sus fuerças por enmendar aquel yerro e andava con la espada toda tinta de sangre matando e feriendo en ellos» (277).

33 «Después levantóse muy ledo, abraçando a todos e diziéndoles cosas de grande amor, especialmente a Laurena prometiéndole de restituylla en su señorío e de pagalle a ella e a sus vasallos quanto daño avían recibido de los turcos, pues él avía sido en ayudalles» (346).

${ }^{34}$ Con respecto la relación entre mitología clásica y libros de caballerías vid. Marín Pina (1998 y 2010) y Martín Romero (2008a).
} 
En los momentos en que aparece esta obra el género se está configurando, tan sólo se cuenta con los textos de Montalvo y con la continuación de Páez de Ribera, Florisando, así como algunas narraciones caballerescas breves y unos pocos textos artúricos ${ }^{35}$. En esos años se está fraguando un modelo caballeresco múltiple, en el que - junto a la perfección mundana de Amadís y la actitud de cruzado de Esplandián- otros héroes, como el religioso Florisando y el humano Palmerín, van dando cuenta de la enorme diversidad que se encontrará en las páginas de estos libros. Con el tiempo vendrán otros caballerescos singulares, como Florindo o Rosián de Castilla ${ }^{36}$, por poner tan sólo dos ejemplos entre tantos otros bien distintos a Amadís. Pero ya en los libros iniciales del género se percibe la heterogeneidad que lo va a caracterizar a lo largo de casi siglo y medio de existencia.

\section{BIBLIOGRAFÍA CITADA}

Aguilar Perdomo, María del Rosario (2001). «La penitencia de amor caballeresca: Lisuarte, Florambel, Felixmarte y otros enfermos de amor», en Julián Acebrón Ruiz (coord.), Fechos antiguos que los cavalleros en armas passaron: estudios sobre la ficción caballeresca. Lleida: Edicions de la Universitat de Lleida, pp. 125-150.

Alvar, Carlos (trad.) (1986). La búsqueda del Santo Grial. Madrid: Alianza Editorial.

Alvar, Carlos (1991). El rey Arturo y su mundo. Diccionario de mitología artúrica. Madrid: Alianza Editorial.

Alvar, Carlos (2002). «Raíces medievales de los libros de caballerías», Edad de Oro. XXI, pp. 61-84.

Amezcua, José (1972). «La oposición de Montalvo al mundo del Amadís de Gaula», Nueva Revista de Filología Hispánica. XXI, pp. 320-337.

Amezcua, José (1984). Metamorfosis del caballero. Sus transformaciones en los libros de caballerías españoles. México: Cuadernos Universitarios, UAM.

Basurto, Fernando (2007). Florindo. Ed. de Alberto del Río Nogueras. Alcalá de Henares: Centro de Estudios Cervantinos.

Beltrán, Rafael (2004-2005). «Tiemblan las carnes del valiente ante la batalla: claves caballerescas para el episodio de los requesones en la celada y el león manso $(D Q, I I, X V I I) »$, Letras. L-LI, pp. 39-50.

Bueno Serrano, Ana Carmen (2005). «Motivos literarios de la representación de la violencia en los libros de caballerías castellanos (1508-1514): enanos, doncellas y dueñas anónimas», en Rafael Alemany, Josep Lluis Martos y Josep Miquel Manzanero (eds.), Actes del X Congrés Internacional de l'Associació Hispànica de Literatura Medieval. Alicante: Institut Interuniversitari de Filología Valenciana, pp. 441-452.

${ }^{35}$ Vid. Alvar (2002), que actualiza y ofrece nuevos datos frente a los estudios de Entwistle (1925) y Lida de Malkiel (1959).

${ }^{36}$ Vid. Río Nogueras (1988). Este libro de caballerías ha sido recientemente editado también por Río Nogueras (Basurto, 2007); en cuanto a Rosián de Castilla, vid. Sales Dasí (2001) y la citada edición debida a Ricardo Arias (Romero de Cepeda, 1979). Otros caballeros singulares protagonistas de libros de caballerías podrían añadirse, sirvan éstos como muestras de la enorme diversidad heroica de los libros de caballerías. 
Cacho Blecua, José Manuel (1979). Amadís: heroísmo mítico-cortesano. Zaragoza: Cupsa Editorial / Universidad de Zaragoza.

Campos García Rojas, Axayacatl (2005). «Las lenguas extranjeras en los libros de caballerías: Amadís de Gaula y Las Sergas de Esplandián», en Rafael Alemany, Josep Lluís Martos y Josep Miquel Manzanero (eds.), Actes del X Congrés Internacional de l'Associació Hispànica de Literatura Medieval. Alicante: Institut Interuniversitari de Filologia Valenciana, vol. I, pp. 487-497.

Cartagena, Alonso (1995). Doctrinal de los cavalleros. Ed. de José María Viña Liste. Santiago de Compostela: Universidade de Santiago de Compostela.

Entwistle, William James (1925). The Arthurian Legend in the Spanish Peninsula. LondresToronto: J. M. Dent \& Sons.

Ferrario de Orduna, Lilia (2000). «Palmerín de Olivia y Primaleón: algunas consideraciones sobre su autoría», en Margarita Freixas y Silvia Iriso (eds.), Actas del VIII Congreso de la Asociación Hispánica de Literatura Medieval (Santander, 22-26 septiembre de 1999). Santander: Consejería de Cultura del Gobierno de Cantabria / Asociación Hispánica de Literatura Medieval, pp. 717-728.

Ferrario de Orduna, Lilia (2005). «Nuevamente en torno a Primaleón y el problema de su autoría», en Rafael Alemany, Josep Lluís Martos y Josep Miquel Manzanero (eds.), Actes del X Congrés Internacional de l'Associació Hispànica de Literatura Medieval. Alicante: Institut Interuniversitari de Filologia Valenciana, vol. II, pp. 721-729.

Gili Gaya, Samuel (1947). «Las Sergas de Esplandián como crítica de la caballería bretona», Boletín de la Biblioteca Menéndez y Pelayo. XXIII, pp. 103-111.

Guijarro Ceballos, Javier (2007). «La nave encantada», en El Quijote cervantino y los libros de caballerías: calas en la poética caballeresca. Alcalá de Henares: Centro de Estudios Cervantinos, pp. 139-183.

Laspalas, Javier (2006). «El problema de la insinceridad en cuatro tratados de cortesía del Renacimiento», en Rocío García Bourrellier y Jesús M. ${ }^{a}$ Usunáriz (eds.). Aportaciones a la historia social del lenguaje: España. Siglos XIV-XVIII. Madrid, Frankfurt am Main: Iberoamericana / Vervuert, pp. 27-55.

Lida de Malkiel, M. ${ }^{a}$ Rosa (1959). «Arthurian Literature in Spain and Portugal», en Roger Sherman Loomis, Arthurian Literature in the Middle Ages. Oxford: At Clarendon Press, pp. 406-418.

Lucía Megías, José Manuel (2000). Imprenta y libros de caballerías. Madrid: Ollero \& Ramos.

Lucía Megías, José Manuel y Emilio José Sales Dasí (2002). «La otra realidad en los libros de caballerías. (I) Los enanos», Rivista di Filologia e Letterature Ispaniche, V, pp. 923.

Lucía Megías, José Manuel y Emilio José Sales Dasí (2005). «La otra realidad en los libros de caballerías. (II) Las damas y doncellas lascivas», en Rafael Alemany, Josep Lluis Martos y Josep Miquel Manzanaro (eds.), Actes del X Congrés Internacional de l'Associació Hispànica de Literatura Medieval. Alicante: Institut Interuniversitari de Filología Valenciana, pp. 1007-1022.

Lucía Megías, José Manuel y Emilio José Sales Dasí (2007). «La otra realidad social en los libros de caballerías. (III). El caballero «anciano»», en Armando López Castro y Luzdivina Cuesta Torre (eds.), Actas del XI Congreso Internacional de la Asociación Hispánica de Literatura Medieval. León: Universidad de León, pp. 783-805.

Mancini, Guido (1966). Introduzione al «Palmerín de Olivia». Studi sul «Palmerín de Olivia». Vol. II. Pisa: Istituto di Letteratura Spagnola e Ispano-Americana / Università degli Studi di Pisa.

Mancini, Guido (1970). «Introducción al Palmerín de Olivia», en Dos estudios de literatura española. Barcelona: Planeta, pp. 9-202. 
Marín Pina, M. ${ }^{a}$ Carmen (1989). Edición y estudio del ciclo español de los Palmerines. Zaragoza: Servicio de Publicaciones de la Universidad de Zaragoza (Microfichas).

Marín Pina, M. ${ }^{a}$ Carmen (1991). «Nuevos datos sobre Francisco Vázquez y Feliciano de Silva, autores de libros de caballerías», Journal of Hispanic Philology. XV, pp. 117-130.

Marín Pina, M. ${ }^{a}$ Carmen (1998). «Metamorfosis caballeresca de Píramo y Tisbe en el Clarisel de las Flores de Jerónimo de Urrea», en Rafael Beltrán (ed.), Literatura de caballerías y orígenes de la novela. Valencia: Universitat de València, pp. 289-307.

Marín Pina, M. ${ }^{a}$ Carmen (2004). «Introducción» en Giuseppe di Stefano y Daniela Pierucci (eds.), Palmerín de Olivia. Alcalá de Henares: Centro de Estudios Cervantinos.

Marín Pina, M. ${ }^{a}$ Carmen (2010). «La mitología en los libros de caballerías: de la cita comparativa a la aventura mítico-caballeresca», en Claudia Demattè (ed.), Il mondo cavalleresco tra immagine e testo. Trento: Università di Trento, pp. 135-171.

Martín Romero, José Julio (2008a). «La transformación de la materia clásica en materia caballeresca en el Renacimiento», en José María Maestre Maestre, Joaquín Pascual Barea y Luis Charlo Brea (coords.), Humanismo y pervivencia del mundo clásico: homenaje al profesor Antonio Prieto. IV. Alcañiz / Madrid: IEH / CSIC, vol. 1, pp. 2001-2014.

Martín Romero, José Julio (2008b). «La 'verdad disimulada' y el 'juramento ambiguo' en la literatura caballeresca», en José Manuel Lucía Megías y M. ${ }^{a}$ Carmen Marín Pina (eds.), Amadís de Gaula: quinientos años después. Estudios en homenaje a Juan Manuel Cacho Blecua. Alcalá de Henares: Centro de Estudios Cervantinos, pp. 503-523.

Martín Romero, José Julio (2009). «Del fin' amors al neoplatonismo: amor y caballería en la narrativa caballeresca hispánica». Tirant. XI, pp. 119-142.

Martín Romero, José Julio (2010). «Sobre el Endriago amadisiano y sus descendientes caballerescos», en José Manuel Fradejas Rueda, Déborah Dietrick Smithbauer y M. ${ }^{a}$ Jesús Díez Garretas (eds.), Actas del XIII Congreso Internacional de la Asociación Hispánica de Literatura Medieval (Valladolid, 15 al 19 de septiembre de 2009). Valladolid: Ayuntamiento de Valladolid, pp. 1283-1298.

Río Nogueras, Alberto del (1988). «Una trayectoria caballeresca singular. El Don Florindo de Fernando Basurto», Journal of Hispanic Philology. XII, pp. 191-205.

Rodríguez de Montalvo, Garci (1991). Amadís de Gaula. Ed. de Juan Manuel Cacho Blecua. Madrid: Cátedra, 2 vols.

Romero de Cepeda, Joaquín (1979). La historia de Rosián de Castilla. Ed. de Ricardo Arias. Madrid: CSIC / Instituto Miguel de Cervantes.

Romero Tabares, Isabel (2001). «Modelos de mujeres en los libros de caballerías hispánicos. El Rosián de Castilla», en Julián Acebrón Ruiz (ed.), Fechos antiguos que los cavalleros en armas passaron. Estudios sobre la ficción caballeresca. Lleida: Edicions de la Universitat de Lleida, pp. 191-215.

Ruiz de Conde, Justina (1948). El amor y el matrimonio secreto en los libros de caballerías. Madrid: Aguilar Editor.

Sales Dasí, Emilio (2001). «Una crónica caballeresca singular del quinientos: el Rosián de Castilla», en Julián Acebrón Ruiz (ed.), Fechos antiguos que los cavalleros en armas passaron. Estudios sobre la ficción caballeresca. Lleida: Edicions de la Universitat de Lleida, pp.151-190.

Stefano, Giuseppe di (ed.) (1966). Palmerín de Olivia. Pisa: Università di Pisa.

Stefano, Giuseppe di y Daniela Pierucci, eds. (2004). Palmerín de Olivia. Alcalá de Henares: Centro de Estudios Cervantinos.

Thomas, Henry (1952). Las novelas de caballerías españolas y portuguesas. Trad. de Esteban Pujals. Madrid: CSIC.

Fecha de recepción: 26 de abril de 2012

Fecha de aceptación: 20 de septiembre 2012

Revista de Literatura, 2014, vol. LXXVI, n. ${ }^{\circ}$ 152, 425-445, ISSN: 0034-849X, doi: 10.3989/revliteratura.2014.02.014 